\title{
Parentalidades Adotiva e Biológica e Suas Repercussões nas Dinâmicas Conjugais
}

\author{
Mariana Silva Cecílio \\ Universidade Federal do Triângulo Mineiro, MG, Brasil.
}

\author{
Fabio Scorsolini-Comin \\ Universidade Federal do Triângulo Mineiro, MG, Brasil.
}

Resumo: O objetivo deste estudo foi compreender os processos de construção das parentalidades adotivas e biológicas e suas repercussões na conjugalidade. Trata-se de um estudo de caso coletivo, qualitativo e transversal. Foram entrevistados sete casais com filho(s) biológico(s) nascido(s) antes da chegada do(s) adotivo(s). Utilizou-se a técnica da história de vida e a entrevista semiestruturada, totalizando 14 entrevistas. A análise de conteúdo revelou quatro eixos temáticos. A motivação para adoção foi referida como ato tanto de amor quanto de ajuda ao próximo. Observou-se que a transição para a parentalidade, ocorrida com o nascimento do filho biológico, repercutiu de modo mais expressivo na qualidade da relação conjugal que a chegada dos demais filhos, tanto adotivos quanto biológicos. O planejamento do casal para a adoção possibilitou que os ajustes na estrutura familiar não afetassem a conjugalidade e a satisfação no relacionamento amoroso, compreendido como positivo ao longo da experiência parental.

Palavras-chave: Adoção, Parentalidade, Relação Conjugal.

\section{Adoptive and Biological Parenthoods and Their Impact on Marital Dynamics}

\begin{abstract}
This study aims to comprehend the processes of construction of the adoptive and biological parenthoods and their repercussions on conjugality. It's a collective case, qualitative and transversal study. Seven couples with a biological child born before the arrival of an adoptive child were interviewed. Life history technique and semi structured interviews, totaling 14 interviews, were used. Four thematic axes were identified according to the content analysis. The motivation for adoption was referred as an act both of love and of helping others. It was observed that the transition to the parenthood with the birth of the biological child had a repercussion in a more expressive way on the quality of the conjugal relation, than the arrival of other children either adoptive or biological. Couple's planning for adoption favored the conjugality and the satisfaction of the marital relationship, seen as positive throughout the parenthood experience. KeYwords: Adoption, Parenthood, Marital Relationship.
\end{abstract}




\title{
Paternidad Adoptiva y Biológica y Sus Repercusiones en las Dinámicas Conyugales
}

\begin{abstract}
Resumen: El objetivo de este estudio fue comprender los procesos de construcción de las paternidades adoptiva y biológica y sus repercusiones en la vida conyugal. Se trata de un estudio de caso colectivo, cualitativo y transversal. Fueron entrevistadas siete parejas con hijo(s) biológico(s) nascido(s) antes de la llegada del(los) adoptivo(s). Se utilizó la técnica de la historia de vida y la entrevista semiestructurada, totalizando 14 entrevistas. El análisis del contenido reveló cuatro ejes temáticos. La motivación para la adopción fue referida como un acto tanto de amor como de ayuda al próximo. Se observó que la transición para la paternidad ocurrida con el nacimiento del hijo biológico repercutió de modo más expresivo en la calidad de la relación conyugal que la llegada de los demás hijos, tanto adoptivos como biológicos. La planificación de la pareja para la adopción posibilitó que la estructura familiar no afectara la pareja ni la satisfacción en el relacionamiento amoroso, comprendido como positivo a lo largo de la experiencia de paternidad.

Palabras clave: Adopción, Parentesco, Relación Conyugal.
\end{abstract}

\section{Introdução}

A ideia de que a família está em constante transformação permite reflexões sobre como dois importantes circunscritores para a construção das identidades dentro da família, conjugalidade e parentalidade, que parecem se influenciar mutuamente por se tratarem de dimensões constitutivas do psiquismo familiar (Cecílio, \& Scorsolini-Comin, 2013; Magalhães, \& Féres-Carneiro, 2011; Roudinesco, 2003; Zornig, 2010). Nesse cenário de rupturas e continuidades, releituras são possíveis diante das chamadas circunstâncias pós-modernas que denotam a pluralidade e flexibilidade da dinâmica familiar (Cecílio, Scorsolini-Comin, \& Santos, 2013; Vaitsman, 1994).

A expressão "novos arranjos familiares" vem sendo empregada em muitas pesquisas, notadamente da Psicologia, que buscam compreender as dinâmicas familiares que não passam mais pela consideração inequívoca de uma configuração nuclear, heteronormativa e calcada em laços biológicos de parentesco. Um dos arranjos que vêm sendo discutidos contemporaneamente é o de famílias compostas tanto por filhos biológicos quanto adotivos (Otuka, Scorolini-Comin, \& Santos, 2012, 2013), ainda que não seja tão expressiva a visibilidade dessas estruturas no meio científico. Especificamente, o recorte deste estudo debruça-se sobre os arranjos nos quais os filhos adotivos vieram após os filhos biológicos. A principal motivação para elencar esses arranjos é a consideração de que a adoção ocorrida após a chegada dos filhos biológicos poderia ser motivada por elementos não mais ligados exclusivamente à infertilidade dos cônjuges, por exemplo, possibilitando uma melhor compreensão sobre essas famílias, não tão raras em nossa sociedade.

O "ser pai" e o "ser mãe" tendem a derivar de uma concordância trabalhada entre os cônjuges ao decidirem formar uma família. Especificamente na adoção, o processo é permeado por aspectos subjetivos que transcendem os aspectos legais e jurídicos, implicando incertezas, expectativas, ansiedade, fantasias, mitos e dúvidas (Huber \& Siqueira, 2010; Scorsolini-Comin, Amato, \& Santos, 2006; Sequeira, \& Stella, 2014), o que requer que sejam investigadas as reais motivações que legitimam esse desejo. Nos arranjos priorizados neste estudo, de famílias com filhos biológicos e adotivos, esse desejo pode se apresentar a partir de diferentes demandas que ultrapassam a infertilidade dos cônjuges.

A família vem sendo analisada sob a perspectiva das funções parentais, papéis de gênero, aspectos inerentes ao parentesco dos membros, relações de afeto e das repercussões entre os subsistemas. Desse modo, alguns estudos têm apontado que a vivência da parentalidade interfere significativamente na dinâmica conjugal, podendo atualizar sentimentos de rejeição do parceiro ou mesmo de maior intimidade do casal frente ao projeto parental (Jager, \& Botolli, 2011; Menezes, \& Lopes, 2007).

A chamada transição para a parentalidade constitui um momento de especial atenção no ciclo vital, período no qual os futuros pais precisam promover 


\section{Cecílio, Mariana Silva; Scorsolini-Comin, Fabio (2016).}

Parentalidades Adotiva e Biológica.

diversos ajustes para a chegada do(a) filho(a), quer seja biológico ou adotivo. Esses ajustes envolvem tanto aspectos materiais e de rotina como de estruturação do psiquismo e de construção das identidades materna e paterna, justamente pela assunção de novos papéis sociais e familiares. A partir dessas considerações, pode-se investigar de que modo esse processo de construção da parentalidade interfere na conjugalidade ou é auxiliado/facilitado por ela.

As repercussões da parentalidade na conjugalidade constituem uma questão atual que nos obriga a compreender de que modo os diferentes arranjos possibilitam a assunção de diversas formas de ser casal após a chegada dos filhos (Cecílio, \& Scorsolini-Comin, 2013). Obviamente, essas repercussões devem considerar o contexto no qual o casal está envolvido, o planejamento ou não da gestação, a história do casal, a existência ou não de irmãos, a satisfação conjugal, a estrutura familiar, a rede de apoio social constituída, bem como aspectos materiais, financeiros e também ocupacionais dos cônjuges.

De maneira especial, as pesquisas são polarizadas em torno dos estudos sobre a transição para a parentalidade no contexto biológico (Menezes, \& Lopes, 2007) ou dentro do contexto da adoção (Weber, 2010), mas raramente utilizando-se como marco ambas as formas de exercício parental, em um mesmo arranjo (Otuka et al., 2013). Desse modo, questiona-se se as repercussões da parentalidade na conjugalidade seriam diferentes nesses arranjos, haja vista a coexistência de duas modalidades de filiação com características e motivações por vezes distintas. Entende-se que a compreensão das repercussões dessas experiências de parentalidade pode ser significativa para a construção da identidade familiar e da conjugalidade, bem como para a identificação das possíveis necessidades dessas famílias. Tendo como ponto de partida essas considerações, o presente estudo teve por objetivo compreender os processos de construção das parentalidades adotiva e biológica e suas relações com as dinâmicas conjugais em casais com filhos biológicos e adotivos.

\section{Método}

Trata-se de um estudo de caso coletivo amparado na abordagem qualitativa de pesquisa, de corte transversal. A escolha por este tipo de método de investigação deve-se ao objetivo de ampliar a compreensão do objeto de estudo partir de uma multiplicidade de casos que compõem o plano de análise para se estudar um fenômeno (Stake, 2000).

\section{Participantes}

Participaram deste estudo sete casais em união há, pelo menos, dez anos, e que possuíam filho(s) biológico(s) nascido(s) antes da chegada do(s) adotivo(s), sendo o intuito selecionar apenas casais que já tinham construído de modo mais sólido os seus vínculos tanto conjugais como parentais. Os cônjuges foram entrevistados individualmente, totalizando 14 entrevistas. Não houve restrição quanto ao sexo ou idade da criança ou do adolescente e a quantidade de filhos biológicos ou adotivos do casal, bem como a idade dos cônjuges. Além disso, salienta-se que os casais entrevistados realizaram a adoção antes da nova Lei da Adoção (Brasil, 2009). A caracterização da amostra é apresentada na Tabela 1, na seção de Resultados e Discussão.

\section{Instrumentos}

Dois instrumentos foram aplicados face a face com cada cônjuge: (a) Técnica da História de Vida do participante, que visa a investigar de que modo a pessoa constrói explicações e descrições para a própria trajetória de vida até o momento, sendo que o recorte temporal e as experiências narradas como significativas são selecionadas pelo próprio respondente; e (b) Roteiro de entrevista semiestruturada com o participante, elaborado a partir dos objetivos deste estudo, contemplando perguntas sobre a constituição da família, do casal, a dinâmica conjugal, a transição para a parentalidade, os cuidados com os filhos, bem como desafios e potencialidades observados na relação conjugal a partir da chegada dos filhos.

\section{Procedimentos}

\section{Coleta de dados}

Este estudo foi aprovado pelo Comitê de Ética em Pesquisa da universidade de origem dos autores. Os participantes foram localizados a partir da rede de contatos sociais dos pesquisadores, com apoio da técnica da "bola de neve". Os voluntários foram devidamente informados sobre o objetivo da pesquisa e sobre os termos do trabalho. Após a assinatura do Termo de Consentimento Livre e Esclarecido, os dados foram coletados por meio de entrevistas individuais 
audiogravadas realizadas nas residências dos participantes, em locais que garantiam o sigilo das informações e o conforto emocional do respondente.

\section{Análise dos dados}

As entrevistas foram transcritas na íntegra e literalmente. Uma análise vertical do material (de cada entrevista separadamente) permitiu destacar os eixos temáticos encontrados a partir das falas de cada um dos respondentes enquanto, em um segundo momento, realizou-se uma análise horizontal das entrevistas, elencando os pontos de semelhança e diferenças entre as falas dos participantes. Os dados das entrevistas foram organizados por meio da análise de conteúdo temático, com destaque para termos, expressões e ideias mais evocados pelos participantes. As análises horizontais, integrando todos os casos, são apresentadas a partir das categorias construídas com base nas falas dos participantes. A interpretação dos dados foi pautada na perspectiva teórico-metodológica da Rede de Significações - RedSig (Rossetti-Ferreira, Amorim, Silva, \& Carvalho, 2004) e na literatura científica da área. A RedSig é uma abordagem desenvolvimental inspirada em teóricos como Bakhtin, Wallon, Vigotski e Bronfenbrenner que compreende que, ao longo do ciclo vital, diferentes situações, eventos e processos disparam a necessidade de que novas significações sejam produzidas pelas pessoas, com destaque para o meio, as relações proximais e os contextos socioculturais nos quais as pessoas estão inseridas.

\section{Resultados e discussão}

A experiência da parentalidade adotiva e biológica mostra-se relevante não somente para compreender como se constroem os vínculos afetivos, como também para ajudar a desmistificar antigas certezas arraigadas de que a adoção ainda é motivada exclusivamente pela impossibilidade biológica de gerar filhos. Dessa forma, a maneira como são vivenciadas e co-construídas as relações familiares muito dirá do modo como foram estabelecidos e negociados os laços conjugais e parentais durante as trocas afetivas (Rossetti-Ferreira et al., 2004; Zornig, 2010).

Conforme mencionado, sete casais participaram da pesquisa $(\mathrm{N}=14)$. A Tabela 1 caracteriza a amostra, permitindo o mapeamento geral da idade, profissão, tempo de casamento, motivações para recorrerem à prática da adoção e o número de filhos biológicos e adotivos que compõem o seio familiar até o momento das entrevistas. Esta informação mostra-se relevante, visto que o casal 1 havia acabado de se inscrever no Cadastro Nacional para adotar mais uma criança, configurando a segunda adoção.

Observa-se que a idade dos participantes variou entre 43 e 68 anos para as mulheres e entre 44 e 72 anos para os homens, média de tempo de casamento de 33 anos, predomínio da religião católica. Em relação à escolaridade, apenas uma pessoa não concluiu o ensino fundamental (Tabela 1). Em termos da parentalidade adotiva, enquanto quatro casais $(1,2,4$ e 5$)$ passaram pelo processo de adoção que envolve a lista de espera preconizada pela lei, três casais $(3,6$ e 7$)$ obtiveram a guarda de uma criança conhecida, configurando o que é conhecido como adoção direta (Mariano, \& Rossetti-Ferreira, 2008).

Apartirdasfalasdosparticipantes,foramconstruídas as seguintes categorias, analisadas na sequência: (a) A gestação de um novo papel; (b) Um é pouco? A relação de um ou mais irmãos (adotivo e biológico); (c) A motivação para a adoção e o lugar ocupado pelo filho na família; (d) Ajustamento conjugal na parentalidade.

\section{A gestação de um novo papel}

A transição para a parentalidade constitui um momento importante do ciclo vital justamente por promover uma ampliação dos papéis anteriormente centralizados exclusivamente no casal, o que requer ajustes, adaptação e assunção de novas tarefas e necessidades (Huber, \& Siqueira, 2010; Jager, \& Bottoli, 2011; Menezes, \& Lopes, 2007). Nos entrevistados, destaca-se que os casais 1, 4, 5 e 6 anunciaram não terem planejado a gravidez, sendo essencial considerar o que Weber (1999) conjectura sobre a importância de preparação dos pais para se ter um filho, refletindo suas expectativas, medos e fantasias implicados. Dos sete casais, apenas Fátima (casal 1) e Carolina (casal 4) não manifestaram terem desejado ter filhos assim que se casassem, trazendo o que Zornig (2010) discute a respeito da dissociação contemporânea entre casamento e parentalidade iminente.

Referindo-se à inexperiência natural em exercer um novo papel, destaca-se o discurso de Manoel (casal 1): "No momento, não sabia se ria ou se chorava (risos) [...] foi assim meio preocupante, mas foi feliz, foi legal", denotando ter sido um misto de felicidade e preocupação receber a notícia da gravidez da esposa. Além da tensão advinda da transição, a filha biológica nasceu com uma deficiência mental não diagnosticada, exigindo uma 


\section{Cecílio, Mariana Silva; Scorsolini-Comin, Fabio (2016).}

Parentalidades Adotiva e Biológica.

Tabela 1

Identificação dos participantes entrevistados segundo a idade, profissão, tempo de casamento, motivações para a adoção e número de filhos $(N=14)$.

\begin{tabular}{|c|c|c|c|c|c|}
\hline Casal & Idade & Profissão & $\begin{array}{l}\text { Tempo de } \\
\text { casamento } \\
\quad \text { (anos) }\end{array}$ & Motivações para a adoção & Filhos \\
\hline 1 & $\begin{array}{l}44(\mathrm{H}) \\
43(\mathrm{M})\end{array}$ & $\begin{array}{l}\text { Funcionário Público } \\
\text { Farmacêutica }\end{array}$ & 20 anos & $\begin{array}{l}\text { Desejo de ter mais filho seguido do } \\
\text { medo do nascimento de outro filho } \\
\text { deficiente. } \\
\text { Amor e vontade desde a infância. }\end{array}$ & $\begin{array}{l}1 \text { biológico } \\
1 \text { adotivo }\end{array}$ \\
\hline 2 & $\begin{array}{l}54(\mathrm{H}) \\
55(\mathrm{M})\end{array}$ & $\begin{array}{l}\text { Professor Universitário } \\
\text { Escrevente }\end{array}$ & 31 anos & $\begin{array}{l}\text { Questão religiosa. } \\
\text { Vontade desde a infância. }\end{array}$ & $\begin{array}{l}3 \text { biológicos } \\
2 \text { adotivos }\end{array}$ \\
\hline 3 & $\begin{array}{l}72(\mathrm{H}) \\
68(\mathrm{M})\end{array}$ & $\begin{array}{l}\text { Eletricitário aposentado } \\
\text { Professora aposentada }\end{array}$ & 44 anos & $\begin{array}{l}\text { Atitude "caridosa". } \\
\text { Ajudar os pais e a criança } \\
\text { (Parentesco). }\end{array}$ & $\begin{array}{l}2 \text { biológicos } \\
\text { (um falecido) } \\
1 \text { adotivo }\end{array}$ \\
\hline 4 & $\begin{array}{l}53(\mathrm{H}) \\
48(\mathrm{M})\end{array}$ & $\begin{array}{l}\text { Professor Universitário } \\
\text { Dona de casa }\end{array}$ & 25 anos & $\begin{array}{l}\text { Proporcionar melhores condições para } \\
\text { a criança, emocional e financeiramente. }\end{array}$ & $\begin{array}{l}2 \text { biológicos } \\
1 \text { adotivo }\end{array}$ \\
\hline 5 & $\begin{array}{l}54(\mathrm{H}) \\
56(\mathrm{M})\end{array}$ & $\begin{array}{l}\text { Funcionário Público } \\
\text { aposentado } \\
\text { Funcionária Pública } \\
\text { aposentada }\end{array}$ & 28 anos & $\begin{array}{l}\text { Vontade de ampliar a família e devido } \\
\text { à perda do segundo filho por aborto } \\
\text { espontâneo. }\end{array}$ & $\begin{array}{l}1 \text { biológico } \\
1 \text { adotivo }\end{array}$ \\
\hline 6 & $\begin{array}{l}65(\mathrm{H}) \\
60(\mathrm{M})\end{array}$ & $\begin{array}{l}\text { Contador } \\
\text { Auxiliar Judiciário }\end{array}$ & 36 anos & Parentesco. & $\begin{array}{l}3 \text { biológicos } \\
\text { (um falecido) } \\
1 \text { adotivo }\end{array}$ \\
\hline 7 & $\begin{array}{l}70(\mathrm{H}) \\
66(\mathrm{M})\end{array}$ & $\begin{array}{l}\text { Comerciante } \\
\text { aposentado } \\
\text { Comerciante } \\
\text { aposentada }\end{array}$ & 48 anos & Ajudar a criança & $\begin{array}{l}4 \text { biológicos } \\
1 \text { adotivo }\end{array}$ \\
\hline
\end{tabular}

reestruturação do casal para aprender a lidar com suas limitações. Para isso, somou-se a necessidade de elaboração de um luto: "Eu penso que aquela criança que nós esperávamos, que nós amávamos, ela morreu, entendeu? [...] nós passamos a ter outra criança, outra realidade", corroborando com o que Bastos e Deslandes (2008) discutem sobre a reação dos pais ao se depararem com o filho real e as frustrações advindas, entendendo que terá de ressignificar seu desejo e (re)encontro narcísico.

Da mesma forma que Manoel, Fátima (casal 1) e Fábio (casal 5) sentiram euforia e medo quando souberam que iam ser pais pela primeira vez. No casal 2, Batista fala constrangido: "a gente teve as dificuldades de casal do primeiro filho, fizemos algumas burradinhas". No mesmo sentido, como mãe pela primeira vez, Ângela declara: "Foi um horror, porque eu sempre fui dorminhoca e eu achava que a Ana tinha que dormir (risos) [...] custou a cair a ficha [...] Acho que o Batista foi mais maduro do que eu".

Assim como ela, Adriano (casal 5) reforça que a rotina com sua esposa mudou "cem por cento". Estas falas tanto revelam a adaptação e o redimensionamento de responsabilidades, como, no caso de Ângela, alimentam a percepção positiva sobre o marido, indicando um ajustamento e satisfação diante da demanda (Jager, \& Botolli, 2011). Esses sentimentos ambivalentes verbalizados e sentidos, que viriam anunciar o ingresso do casal a um novo subsistema (triádico), são abordados por Prati e Koller (2011), bem como por Menezes e Lopes (2007), que trazem a ideia de que a identidade parental viria redefinir a relação conjugal (Cecílio, \& Scorsolini-Comin, 2013).

Houve prevalência nos discursos dos pais em afirmar que não se encontravam estruturados profissional e financeiramente para receber o primeiro filho, assim como Jorge (casal 7) expressa o peso da mudança em sua responsabilidade: "Desde que mundo é mundo [...] o marido cuidado do trabalho, ele tem que ganhar dinheiro e sustentar a família", corroborando a cristalização do papel arraigado do homem-pai em ser provedor do lar (Bornholdt, Wagner, \& Staudt, 2007; Jager, \& Bottoli, 2011). No entanto, Fátima (casal 1), 
Ângela (casal 2), Carolina (casal 4) e Geisa (casal 7) destacaram como seus maridos se fizeram presentes na divisão de tarefas cotidianas, o que reforça a importância do apoio do cônjuge (Menezes, \& Lopes, 2007), o que pode repercutir positivamente também na conjugalidade.

Outro ponto de destaque relacionado à participação afetiva e efetiva dos pais é ilustrada por Pedro (casal 3), quando menciona ter lido uma revista sobre pais e filhos assim que sua esposa ficou grávida: "Nessa época, por exemplo, os pais eram muito rudes, muito estúpidos, a gente sofreu muito [...] então eu não queria aquilo pros meus filhos, eu queria aprender alguma coisa de como tratá-los, como orientá-los, isso ajuda muito a gente". A partir desse relato, sobressai a ideia do desejo de reparação em relação às figuras parentais, entendendo que a construção da parentalidade deriva da história individual dos pais, de forma a reatualizar fantasias de sua própria infância, colocando em pauta movimentos narcísicos que refletirão nas identificações com a sua própria representação de parentalidade (Zornig, 2010). Dentro desse contexto em que os pais reivindicam um espaço afetivo e efetivo na vida dos filhos, ressalta-se a esposa-mãe como figura catalisadora desse convite de mais amizade e proximidade (Bornholdt et al., 2007; Jager, \& Bottoli, 2011). Além disso, atesta-se uma mudança na própria experiência da paternidade, sendo o homem cada vez consciente desse papel e valorizado pela maior proximidade com os filhos e sua consequente repercussão no desenvolvimento dos mesmos. A figura do pai contemporâneo, mais próximo e participativo, também emergiu neste presente estudo.

\section{Um é pouco? A relação de um ou mais irmãos (adotivo e biológico)}

Pressupondo a importância de uma preparação de todos os membros para a chegada de um irmão no seio familiar, sobretudo se este vier com uma história pré-adotiva, os casais foram questionados sobre a relação entre os irmãos. Goldsmid e Féres-Carneiro (2007) defendem que o irmão executa um importante papel na constituição do sujeito. Nesse sentido, os casais expressaram o desejo de ter uma família ampla, com mais de um filho. Especificamente, Adriano (casal 5) enfatizou o desejo de não ter filho único: "Eu acho, na minha opinião [...] que um filho só não... assim, não completa a família
[...] pra aprender a dividir". Nesta fala, percebe-se a tentativa em explicar o funcionamento do complexo fraterno discutido por Goldsmid e Féres-Carneiro e da necessidade do primogênito aprender a negociar e reorganizar o seu espaço, saindo de uma posição privilegiada, devendo renunciar à posição de exclusividade na relação com os pais.

Fátima menciona que sentiu a necessidade de preparar a filha Laura (com necessidades especiais) para a chegada da irmã (adotiva): "A gente fez um trabalho de leitura com ela [...] sobre adoção [...] Mas mesmo assim foi uma dificuldade, [...] ela teve muito ciúmes, ela adoeceu... [...] o primeiro filho sempre parece que dá uma retrocedida". E quando viu que a irmã não ia mais embora: "ela passava a noite acordada, porque ela sabia que se ela estava acordada a gente tava perto dela". Este discurso vai ao encontro do que Piccinini, Pereira, Marin, Lopes e Tudge (2007) falam sobre a tensão familiar ao receber um novo membro, observando-se que o primogênito apresenta aumento na dependência e comportamentos mais infantilizados, além de problemas relacionados ao sono para reaver atenção dos pais.

Batista (casal 2), Carolina (casal 4), Marta (casal 5) e Amanda (casal 5) comentam que os filhos possuem uma relação natural de irmãos, com brigas, reconciliações e ciúme. Sônia (casal 3) percebia que seus filhos biológicos se preocupavam com a irmã adotiva, levando-a para bailes em sua juventude. Segundo o seu esposo: "você via que ele (David) tinha amor nela", expressando o carinho de primo que acabou se tornando de irmão pela convivência - fruto da adoção direta. No mesmo sentido, Geisa (casal 7) ri ao contar: "É um puxando o saco do outro e falando: 'Não, não fala do fulano que ele não é assim?"”.

Segundo Goldsmid e Féres-Carneiro (2007), o ciúme pode ser derivado de um sentimento de rivalidade e não aceitação em ter que compartilhar o amor pelos pais, auxiliando na construção da personalidade, enquanto o companheirismo e a solidariedade viriam a intensificar o equilíbrio psíquico e estabelecer o sentimento de segurança, podendo reinar relações cúmplices. Assim, os sentimentos ambivalentes seriam comuns, visto que o intuito é garantir um espaço dentro da família (Muniz, \& Féres-Carneiro, 2012).

Partindo desse contexto, ficaria mais fácil compreender o que Fabio (casal 4) conta sobre a criação do vínculo entre seus filhos, em relação a como 


\section{Cecílio, Mariana Silva; Scorsolini-Comin, Fabio (2016).}

Parentalidades Adotiva e Biológica.

os laços fraternos são construídos, investidos e definidos na disposição dos envolvidos: "E o engraçado, as duas (filhas biológicas) tratam ele (filho adotivo) como irmão biológico [...] Não sei se por esse fato da convivência [...] Você não ama uma pessoa que você não conhece, mas depois que você passa a conviver".

Como o ser humano é relação e constrói-se na relação com o outro (Rossetti-Ferreira et al., 2004), Fabio estaria dizendo que o amor é construído na disposição dos envolvidos, durante as trocas afetivas, sendo importante frisar a importância da qualidade da relação (Cecílio, \& Scorsolini-Comin, 2013; Goldsmid, \& Féres-Carneiro, 2007). Assim, todos os casais insistiram que seus filhos aprenderam a amar, respeitar e criar um espaço de experiências, gerando um sentimento de companheirismo na vida adulta, repercutindo de forma prazerosa na relação conjugal sob o legado de que executaram bem seus papéis.

\section{A motivação para a adoção e o lugar ocupado pelo filho na família}

Todos os casais relataram o desejo de ter filhos biológicos, mas apenas Fátima anunciou que desde sua infância queria ser mãe adotiva. Em relação à motivação para ampliar a família por meio de um laço não consanguíneo, faz-se importante elucidar que a adoção, a partir das falas, possivelmente aconteceu: por amor (Fátima, casal 1), por altruísmo (Ângela e Batista, casal 2; Fabio e Carolina, casal 4; Jorge e Geisa, casal 7), para vivenciar o exercício da parentalidade devido à deficiência da primogênita (Manoel, casal 1), por caridade e/ou solidariedade (Pedro e Sônia, casal 3; Flávio e Amanda, casal 6) e pela impossibilidade de gestar outro filho biológico (Adriano e Marta, casal 5).

É imprescindível dizer que as motivações categorizadas não foram comunicadas de forma isolada, visto que os discursos ora perpassavam por uma ou outra conotação, apresentando tanto um lado financeiro como emocional. De modo geral, predominaram discursos altruístas. Pode-se afirmar que existe, em todas as entrevistas, uma linha tênue entre amor e altruísmo, como expresso na fala de Fátima:

O filho biológico você quis por no mundo, foi um sentimento 'egoístico' ao pensar 'ai, um ser do meu sangue, um ser que vai se parecer comigo' [...] e o adotivo é um amor muito maior porque você não se preocupa com sangue [...], não sabe a genética [...] você apenas ama e espera os dias correrem.
Observam-se os significados atribuídos para diferenciar as motivações relacionadas às modalidades de parentalidade (adotiva ou biológica). Também foi encontrado nos discursos dos casais que as motivações estariam intimamente relacionadas à modalidade de adoção (plena ou direta) e, muitas vezes, perpassadas pela religião.

Os casais 3, 6 e 7 encontram-se enredados em uma malha que compreende não somente seu núcleo familiar, mas também a família biológica de seus respectivos filhos dos quais obtiveram a guarda. Esta informação sugere a metáfora da rede em que as pessoas e seus processos de desenvolvimento poderão se reconfigurar conforme o momento e as características das pessoas em interação (Rossetti-Ferreira et al., 2004).

Sobre essa modalidade de adoção (direta), vigoraram motivações baseadas no sentimento de fazer uma caridade ou ser solidário com a família de origem: "Foi muito bom, porque a gente vê que a gente tá fazendo... em termos certo, seria uma caridade!" (Pedro, casal 3), "Aí o promotor descobriu que ela era minha parente, [...] falou que nós era as pessoas exatas" (Amanda, casal 6) e "não saí procurando uma criança pra adotar, ela veio na minha porta [...] isso é uma coisa por Deus" (Geisa, casal 7). Em outras palavras, entendemos que a adoção não ocorreu como uma preferência em termos de parentalidade.

Quanto aos casais 1, 2, 4 e 5, que acompanharam as vicissitudes do processo adotivo e aguardaram na fila de espera, apreenderam-se sensações de ansiedade, o sentimento de estarem grávidos emocionalmente e a escolha ou não pelas características físicas da criança. Batista (casal 2), por exemplo, desejava uma criança com até dois anos, mas ao ir à instituição e sentir-se "escolhido", acabou adotando um casal de irmãos negros com seis e dois anos e meio de idade.

Em relação às motivações desses casais, com forte conotação altruísta, seguem alguns discursos: "mais pela questão religiosa, mais pela questão da humanidade, [...] visão de mundo" (Batista, casal 2), "ajudar alguém financeiramente [...] é uma coisa, mas você dar amor e tá junto no dia a dia [...] traria muito prazer pra mime eu poderia tá sendo útil pra alguém [...]”(Fabio, casal 4). No entanto, deve ser mencionado que o intuito não é dizer que uma motivação é melhor ou mais correta que outra, até porque, segundo Levinzon (2004), a vontade de ajudar ou o fato de amar uma criança não são motivos suficientes, sendo fundamental que o vínculo de filiação se sustente em discursos duradouros. 
Deve-se destacar a interação entre o relacionamento estabelecido com os filhos (adotivos e biológicos) e os diferentes relacionamentos sociais nos quais estavam inseridos, atravessados pela cultura, fatores ideológicos e relações de poder que compõem o conceito de matriz sócio-histórica (Rossetti-Ferreira et al., 2004). Isso equivale a destacar que, para compreender as histórias desses participantes, deve-se explorar tanto as matrizes individuais dos relacionamentos interpessoais estabelecidos no seio familiar (pais, filhos, irmãos) quanto o modo como o exercício da parentalidade e a adoção são significados em nosso contexto, por exemplo. Assim, o meio pode repercutir no modo como os casais constroem explicações para a construção da conjugalidade e da parentalidade.

Socialmente, percebe-se uma maior compreensão quando a adoção vem associada à infertilidade do casal ou de um dos cônjuges. Mas no recorte realizado no presente estudo, a motivação para adotar quando já se possui filhos parece disparar posicionamentos que recuperam discursos valorizados, como o da solidariedade. Assim, o casal adquire um novo status, não apenas de pais ou de uma família, mas de pessoas engajadas socialmente, altruístas e não egoístas. Há que se esclarecer que essa motivação, de ajudar o outro, tem sido cada vez mais combatida em cursos preparatórios para a adoção e em avaliações realizadas por profissionais da Psicologia e do Serviço Social, uma vez que há a necessidade de que os pais manifestem o desejo de assumir uma parentalidade, independentemente do fato de estarem ajudando ou não uma pessoa em acolhimento institucional, por exemplo (Hueb, Farinelli, Azôr, Cordeiro, \& Tuma, 2014). Prioriza-se, desse modo, notadamente a partir da nova lei da adoção (Brasil, 2009), a construção de vínculos entre pais e filhos, não entre pessoas que ajudam e aquelas que são ajudadas.

Em relação ao lugar ocupado pelo filho no imaginário parental, alguns discursos são destacados: "Você tem os filhos normais como adotivos, mas jamais eu transpareço" (Flávio, casal 6), "Se não der certo a gente devolve" (Sônia, casal 3), "Meu marido é que sempre fala que o Fabrício foi o filho que eu perdi que veio por outros meios" (Marta, casal 5), "Chegava uma hora, duas horas da manhã [...] e não tem como você falar que não, [...] porque a todo momento ele sabia que não era meu filho, eu era pai de criação!" (Jorge, casal 7). É possível perceber o quanto é preciso elaborar certas questões, como a perda (luto) e o sentimento de inadequação por não serem os "pais verdadeiros", não podendo a adoção se configurar como um meio de resolução de problemas pessoais ou sociais (Gondim et al., 2008; Schettini, Amazonas, \& Dias, 2006) que podem dificultar a internalização do filho. Alguns discursos acerca da adoção mostram diferentes níveis de maturidade dos pais em relação a essa experiência da parentalidade, relatos permeados, por vezes, com preconceitos, dúvidas, inseguranças e ausência de uma maior elaboração de todo esse processo, o que pode repercutir nas práticas parentais e até mesmo no relacionamento entre os filhos. Em relação ao reconhecimento das singularidades de cada filho, de forma a promover um ambiente saudável, Fabio (casal 4) aponta seu ponto de vista:

\footnotetext{
Cada criança tem sua particularidade, [...] tem seu caráter, o seu jeito de ser, tanto que as minhas duas filhas biológicas são completamente diferentes uma da outra, também o Raul (adotivo) é completamente diferente das duas e ainda tem a diferença de sexo que eu acho que influencia muito [...]. Minhas filhas eram mais responsáveis, mais estudiosas, o Raul é o contrário (risos).
}

Destaca-se a naturalidade com que fala das diferenças entre os três filhos, sem categorizá-los entre adotivo e biológico, pontuando a ideia de que cada pessoa é única, com seus limites e potencialidades, além da concepção sociocultural de que meninas tendem a ser mais esforçadas e dedicadas que meninos. Assim como Fabio, percebeu-se que os casais 1, 2 e 5 esboçaram explicitamente que criaram um espaço para cada filho e respeitaram as suas identidades, o que é compreendido como uma postura adequada pela literatura científica (Cúneo et al., 2007).

\section{Ajustamento conjugal na parentalidade}

Os casais, em geral, demonstraram proximidade e entendimento ao passarem por cada transição, destacando que o primeiro filho exigiu mais de ambos enquanto pais e casal. Nas palavras de Fátima (casal 1): "Eles (os cônjuges) superam com o primeiro filho todas as dificuldades. O segundo filho, independente se é biologico ou adotivo, é bem mais fácil pro casal". Em complemento, anuncia como driblou as dificuldades: "Como a gente tem muita dificuldade em sair, a gente começou a implantar a nossa rotina e ter nossa vida social dentro de casa com elas duas, né?!". 


\section{Cecílio, Mariana Silva; Scorsolini-Comin, Fabio (2016).}

Parentalidades Adotiva e Biológica.

Essa iniciativa demonstrou que as pessoas podem se mostrar ativas em um contexto, negociando seus limites em meio a conflitos e crises, permitindo percursos até então inesperados (Rossetti-Ferreira et al., 2004).

Assim como Jorge (casal 7), Adriano (casal 5) é enfático ao falar sobre a mudança percebida: "Teve seus altos e baixos, como todo casal, mas foi bom, graças a Deus. Nós superamos todos nossos problemas". Assim como Fátima (casal 1), Carolina (casal 4) e Marta (casal 5) explicitaram uma perda de espaço e liberdade ou uma maior redistribuição do seu tempo por ter que se dedicar a um outro membro que exige atenção. Fabio (casal 4) traz em sua fala a repercussão que sentiu em sua vida a dois:

Até então, antes de ter o filho, a gente planejava muito o dia a dia nosso em função dos dois, aí depois que vieram os filhos o planejamento era muito mais em função dos filhos do que propriamente dos dois, mas esse fato, na minha opinião, ajudou a unir o casal, acho que foi uma experiência válida [...] pra vida conjugal.

Observa-se que o casal, até então centrado em suas aspirações mútuas, precisa se reorganizar para exercer a parentalidade. Aqui identificamos a adaptação às novas rotinas e demandas, sendo fundamental a negociação de papéis (Prati ,\& Koller, 2011; Rossetti-Ferreira et al., 2004). O impacto causado pela parentalidade foi compreendido como fundamental para o amadurecimento da relação conjugal, dando indícios de que a experiência contribuiu para a superação dos desajustes, em maior ou menor grau, no relacionamento.

Amanda (casal 6) é a única a manifestar uma mudança relacionada à intimidade: "Acho que tinha algumas dificuldades, porque meus filhos sempre dormiam no meu quarto, né, quando era pequeno, [...] mas era a criação da gente [...] diferente de hoje. Então, a gente se resguardava, a gente ia vivendo conforme podia". A presente fala permite pensar nas dimensões temporais sugeridas pela RedSig frente à comparação entre gerações e a mudança de costumes e mesmo do que se permite em termos de espaço conjugal e de comunicação entre os cônjuges. Observa-se, nesse sentido, que, contemporaneamente, há mais espaço para que os cônjuges conversem, tragam suas percepções e possam explorar formas mais adequadas e prazerosas no que se refere ao exercício da conjugalidade.
Destacam-se outras falas sobre os impactos sentidos na dinâmica conjugal: "Não. Só tivemos abalo quando morreu a filha" (Flávio, casal 6) e "Depois que descobrimos o problema dela (filha com deficiência mental), isso aí foi realmente um buraco pra gente, no início" (Manoel, casal 1). Ambas as falas destacam a necessidade de elaboração de um luto, sugerindo ter sido um desafio enfrentado pelos casais, sendo no caso de Flávio uma dor ainda não cicatrizada pela perda da filha inesperadamente. Geisa (casal 7) inicia dizendo "Normal" sobre a rotina conjugal perante o exercício parental, mas completa colocando a idade como impacto na conjugalidade: "Agora já tá no fim, já tem doença, já modifica as coisas".

Pedro e Sônia (casal 3), por sua vez, ressaltam que não sentiram efeitos negativos em sua relação: "Se eu vou fazer qualquer coisa [...] vamos conversar, estou querendo fazer assim, o que você acha?" (Pedro) e "Teve mudança pra melhor [...] Continuou a mesma coisa, com mais alegria" (Sônia). Enquanto ela mencionou os filhos como ponto de união, ele ressaltou o diálogo como ponto de cumplicidade, assim como Marta (casal 5) pontuou a comunicação e a divisão de tarefas (Menezes, \& Lopes, 2007; Prati, \& Koller, 2011).

Partindo-se do que Ferreira (2008) traz sobre uma ligeira saliência na satisfação conjugal em famílias adotivas, Carolina (casal 4) relata sobre o planejamento do casal para receber Raul mesmo diante da resistência da família extensa, bem como mostra-se como mediadora da criança em relação ao contexto em que esta será inserida: "Eu comentava com o Fabio: o que importa é nós dois, porque quem vai dar carinho, quem vai dar família pra ele somos nós [...] e o resto vai ter que aprender a aceitar e vai ter que curtir ele".

No mesmo sentido, Adriano (casal 5) exprime como sentiu/reagiu ao projeto parental em comum acordo com a esposa: "Reagimos bem, a gente já tava preparado pra isso". Ressalta-se, mais uma vez, o que Weber (1999) afirma sobre a importância de preparar-se para ter e receber um filho, dando indícios de relação com a repercussão na dinâmica familiar. Além disso, acrescenta-se que, diante da gravidez emocional e simbólica pela qual os casais postulantes a adoção passam durante o período de espera considerado como transição para a parentalidade adotiva, o homem-pai se sente mais participativo, podendo gestar seu filho emocionalmente sem se sentir preterido (Gondim et al., 2008; Huber, \& Siqueira, 2010; Sequeira, \& Stella, 2014). 
Dois pontos foram abordados pelo casal 2. Sobre o relacionamento, a partir da experiência da parentalidade, Batista menciona: "Foi muito bom [...] e acho que as crianças também percebiam isso. [...] acho que fortaleceu o casamento", como destacado por alguns autores (Cicco, Paiva, \& Gomes, 2005; McCoy, Cummings, \& Davies, 2009). Ângela relata outro aspecto sobre o que sentiu: "Acho que pra mim não mudou muita coisa não [...] eu sempre fui muito apaixonada pelo meu marido, pra mim só veio completar [...] ficar mais forte o nosso relacionamento". Nessa fala, observa-se o que ela desperta sobre a importância da qualidade da relação constituída anteriormente à experiência da parentalidade (Magalhães, \& Féres-Carneiro, 2011; Menezes, \& Lopes, 2007), entendendo que as respostas às demandas serão fruto do envolvimento emocional do casal, ajudando na preservação da conjugalidade.

Desse modo, pode-se concluir que a repercussão da parentalidade para a conjugalidade deve se balizar a partir dos vínculos estabelecidos antes da chegada dos filhos, bem como no planejamento conjunto acerca de como essa família irá se estruturar. As repercussões conjugais são avaliadas como positivas, ainda que ajustes tenham sido necessários. Tais ajustes, no entanto, não são referidos como dificultadores do relacionamento conjugal nem associados às modalidades de parentalidade. Assim, o desafio da parentalidade, nesses casais, não esteve associado ao fato dos filhos serem ou não biológicos.

Uma possível explicação para isso reside no fato de que a adoção ocorreu após o nascimento dos filhos biológicos e envolveu planejamento do par, em contraposição à primeira gestação, ocorrida de modo não planejado, em alguns casais. Também a adoção se processou quando os cônjuges estavam mais maduros, de modo que a chegada de um novo membro, embora tenha impactado a estrutura inicial, não tenha repercutido no sentido de afastar os cônjuges ou imporlhes dificuldades maiores. Mesmo com a maior mobilização do casal em torno da transição para a parentalidade, não se exclui a possibilidade que os novos filhos promovam nos casais necessidades de ajustes, o que deve ser acompanhado constantemente.

\section{Considerações Finais}

Os cônjuges quanto pais ressaltaram não acreditar que exista diferença entre filhos biológicos e adotivos, entendendo que cada um se define a partir das relações construídas e significadas. Observou-se a importância de um preparo maior nos casais que possam ter se sentido na obrigação de acolher uma criança, dificultando a consolidação de um laço afetivo ou a percepção de se sentirem ou agirem como pais. Vale destacar que esses casais que obtiveram a guarda não pronunciaram desejar ampliar a família em termos de parentalidade.

Especificamente em relação ao objetivo desta pesquisa, foi possível observar que os casais apresentaram maior dificuldade durante a transição para a parentalidade, experimentando sentimentos ambivalentes. O pai, destituído de seu papel de espectador, apareceu como recurso de apoio e estabilidade emocional para a esposa-mãe em momentos e decisões a serem tomadas. A chegada dos demais filhos foi mencionada como mais tranquila e prazerosa, mas que com os filhos adotivos exigiu-se maior preparo emocional e envolvimento do casal frente às adaptações necessárias, como conversar com os filhos biológicos sobre a chegada do irmão ou da irmã.

A repercussão na dinâmica conjugal, sobretudo positiva, pode se remeter ao sentimento de que as dificuldades foram superadas ou atenuadas a partir do prazer de exercer a parentalidade, mas percebeu-se a necessidade de mais estudos que abarquem ambas as formas de parentalidade juntas para que intervenções, quando necessárias, auxiliem esses casais. Mesmo reconhecendo as limitações deste estudo, como a composição de uma amostra por conveniência, contribui-se com a maior visibilidade desses arranjos e suas possíveis especificidades em torno da ampliação do conceito de família em nossa sociedade.

\section{Referências}

Bastos, O. M., \& Deslandes, S. F. (2008). A experiência de ter um filho com deficiência mental: narrativas de mães. Cadernos de Saúde Pública, 24(9), 2141-2150. doi:10.1590/S0102-311X2008000900020

Bornholdt, E.A., Wagner, A. \& Staudt, A.C.P. (2007). A vivência da gravidez do primeiro filho à luz da perspectiva paterna. Psicologia Clínica, 19(1), 75-92. Recuperado de http://www.academia.edu/19790371/A_viv\%C3\%AAncia_da_gravidez_do_primeiro_filho_\%C3\%A0_luz_da_perspectiva_paterna

Brasil (2009, 4 de agosto). Lei n. 12.010, de 3 de agosto de 2009. Dispõe sobre adoção. Brasília. Diário Oficial da União, Seção 1. 
Cecílio, M. S., \& Scorsolini-Comin, F. (2013). Relações entre conjugalidade e parentalidades adotiva e biológica. Psico (Porto Alegre), 44(2), 245-256. Recuperado de http://revistaseletronicas.pucrs.br/ ojs/index.php/revistapsico/article/view/11515

Cecílio, M. S., Scorsolini-Comin, F., \& Santos, M. A. (2013). Produção científica sobre adoção por casais homossexuais no contexto brasileiro. Estudos de Psicologia (Natal), 18(3), 507-516. doi:10.1590/S1413-294X2013000300011

Cicco, M. F., Paiva, M. L. S. C., \& Gomes, I. C. (2005). Família e conjugalidade: O sintoma dos filhos frente à imaturidade do casal parental. Psicologia Clínica, 17(2), 53-63. doi: 10.1590/S0103-56652005000200005

Cúneo, L.A., Pella, M.E.B., Castiñeira, E., Márquez, A. F., Felbarg, D., \& Muchenik, J. (2007). Relaciones fraternas en la adopción. Archivos Argentinos de Pediatría, 105(1), 74-76. Recuperado de http://www.scielo.org.ar/scielo.php?pi$\mathrm{d}=$ S0325-00752007000100016\&script=sci_arttext

Ferreira, J. M. A. (2008). Satisfação conjugal e parentalidade biológica e adoptiva. Dissertação de Mestrado, Faculdade de Psicologia e de Ciências da Educação, Universidade de Lisboa, Lisboa.

Goldsmid, R., \& Féres-Carneiro, T. (2007). A função fraterna e as vicissitudes de ter e ser um irmão. Psicologia em Revista, 13(2), 293-308. Recuperado de http://www.pucminas.br/ imagedb/documento/DOC_DSC_NOME_ARQUI20080521145906.pdf

Gondim, A. K., Crispim, C. S., Fernandes, F. H. T., Rosendo, J. C., Brito, T. M. C., Oliveira, U. B. et al. (2008). Motivação dos pais para a prática da adoção. Boletim de psicologia, 58(129), 161-170. Recuperado de http://pepsic.bvsalud.org/scielo.php?pi$\mathrm{d}=$ S0006-59432008000200004\&script=sci_arttext

Huber, M. Z., \& Siqueira, A.C. (2010). Pais por adoção: A adoção na perspectiva dos casais em fila de espera. Psicologia: Teoria e Prática, 12(2), 200-216. Recuperado de http://pepsic.bvsalud.org/scielo.php?pi$\mathrm{d}=$ S1516-36872010000200014\&script=sci_abstract

Hueb, M. F. D., Farinelli, M. R., Azôr, A. M. G. C. C. V., Cordeiro, E. G., \& Tuma, A. (2014). A experiência do Grupo Interinstitucional Pró-Adoção na cidade de Uberaba (MG): Compartilhando saberes e práticas. In F. Scorsolini-Comin, L. V. Souza, \& S. M. Barroso (Orgs.), Práticas em psicologia: saúde, família e comunidade (pp. 275-304).
Uberaba, MG: Editora da Universidade Federal do Triangulo Mineiro.

Jager, M. E., \& Bottoli, C. (2011). Paternidade: vivência do primeiro filho e mudanças familiares. Psicologia: Teoria e Prática, 13(1), 141-153. Recuperado de http://pepsic.bvsalud.org/scielo.php?pi$\mathrm{d}=\mathrm{S} 1516-36872011000100011 \&$ script=sci_arttext

Levinzon, G. K. (2004). Adoção. São Paulo, SP: Casa do Psicólogo.

McCoy, K., Cummings, E. M., \& Davies, P. T. (2009). Constructive and destructive marital conflict, emotional security and children's prosocial behavior. Journal of Child Psychology and Psychiatry, 50(3), 270-279. doi:10.1111/j.1469-7610.2008.01945.x

Magalhães, A. S., \& Féres-Carneiro, T. (2011). Em busca de uma conjugalidade perdida: Quando a parentalidade prevalece. In T. Féres-Carneiro (Org.), Casal e família: conjugalidade, parentalidade e psicoterapia (pp. 161-172). São Paulo, SP: Casa do Psicólogo.

Mariano, F. N., \& Rossetti-Ferreira, M. C. (2008). Que perfil da família biológica e adotante, e da criança adotada revelam os processos judiciais? Psicologia: Reflexão e Crítica, 21(1), 11-19. doi:10.1590/S0102-79722008000100002

Menezes, C. C., \& Lopes, R. C. S. (2007). Relação conjugal na transição para a parentalidade: Gestação até dezoito meses do bebê. PsicoUSF, 12(1), 83-93. doi:10.1590/S1413-82712007000100010

Muniz, A. A. M., \& Féres-Carneiro, T. (2012). Função fraterna: reflexões a partir do filme Príncipe das Marés. Psicologia em Revista, 18(1), 41-56. doi:10.5752/P.1678-9563.2012V18N1P41

Otuka, L. K., Scorsolini-Comin, F., \& Santos, M. A. (2012). Adoção suficientemente boa: experiência de um casal com filhos biológicos. Psicologia: Teoria e Pesquisa, 28(1), 73-82. doi:10.1590/S0102-37722012000100007

Otuka, L. K., Scorsolini-Comin, F., \&Santos, M.A. (2013). Adoção tardia por casal divorciado e com filhos biológicos: novos contextos para a parentalidade. Estudos de Psicologia (Campinas), 30(1), 89-99. doi:10.1590/S0103-166X2013000100010

Piccinini, C., Pereira, C., Marin, A., Lopes, R., \& Tudge, J. (2007).Onascimentodosegundofilhoeasrelaçõesfamiliares. Psicologia:Teoriae Pesquisa, 23(3), 253-262. doi:10.1590/S0102-37722007000300003

Prati, L. E., \& Koller, S.H. (2011). Relacionamento conjugal e transição para a coparentalidade: perspectiva da 
psicologiapositiva. PsicologiaClínica,23(1),103-118. doi:10.1590/S0103-56652011000100007

Rossetti-Ferreira, M. C., Amorim, K. S., Silva, A. P. S., \& Carvalho, A. M. A. (Orgs.) (2004). Rede de significações eo estudo do desenvolvimento. Porto Alegre, RS: Artmed.

Roudinesco, E. (2003). A família em desordem. (A. Telles, Trad.). Rio de Janeiro, RJ: Jorge Zahar.

Schettini, S. S. M., Amazonas, M. C. L. A., \& Dias, C. M. S. B. (2006). Famílias adotivas: Identidade e diferença. Psicologia em Estudo, 11(2), 285-293. doi:10.1590/S1413-73722006000200007

Scorsolini-Comin, F., Amato, L. M., \& Santos, M. A. (2006). Grupo de apoio para casais pretendentes à adoção: a espera compartilhada do futuro. Revista da SPAGESP, 7(2), 40-50. Recuperado de http://pepsic.bvsalud.org/scielo.php?script=sci_arttext\&pid=S1677-29702006000200007

Sequeira, V. C., \& Stella, C. (2014). Preparação para a adoção: grupo de apoio para candidatos. Psicologia: Teoria e Prática, 16(1), 69-78. Recuperado de http://pepsic.bvsalud.org/scielo.php?script=sci_arttext\&pid=S1516-36872014000100006

Stake, R. E. (2000). Case studies. In: N. K. Denzin, \&Y. S. Lincoln (Eds). Handbook of qualitative research. London: Sage.

Vaitsman, J. (1994). Flexíveise plurais: identidade, casamento e família em circunstâncias pós-modernas. Rio de Janeiro, RJ: Rocco.

Weber, L. N. D. (1999). Aspectos psicológicos da adoção. Curitiba, PR: Juruá.

Weber, L. N. D. (2010). Pais e filhos por adoção no Brasil: Características, expectativas e sentimentos. Curitiba, PR: Juruá.

Zornig, S. M. A. (2010). Tornar-se pai, tornar-se mãe: o processo de construção da parentalidade. Tempo Psicanalítico, 42(2), 453-470. Recuperado de http://pepsic.bvsalud.org/scielo.php?pi$\mathrm{d}=$ S0101-48382010000200010\&script=sci_abstract

\section{Mariana Silva Cecílio}

Psicóloga e mestranda em Psicologia pela Universidade Federal do Triângulo Mineiro. Bolsista da CAPES.

E-mail:mari_cecilio@hotmail.com

\section{Fabio Scorsolini-Comin}

Doutor em Psicologia pela Universidade de São Paulo, Ribeirão Preto - SP. Brasil. Docente do Programa de Pós-graduação em Psicologia da Universidade Federal do Triângulo Mineiro, Uberaba-MG. Brasil.

E-mail: fabioscorsolini@gmail.com

\section{Endereço para envio de correspondência:}

Prof. Dr. Fabio Scorsolini-Comin, Programa de

Pós-graduação em Psicologia da Universidade Federal do Triângulo Mineiro. Rua Conde de Prados, 155, Abadia, Uberaba-MG, CEP: 38025-260.

Recebido 26/12/2014

Aprovado 20/01/2016

Received 12/26/2014

Approved 01/20/2016

Recibido 26/12/2014

Aceptado 20/01/2016

\section{Agradecimentos:}

Os autores agradecem ao CNPq pela bolsa de iniciação científica concedida à primeira autora para a realização do presente estudo.

Como citar: Cecílio, M. S., \& Scorsolini-Comin, F. (2016). Parentalidades adotiva e biológica e suas repercussões nas dinâmicas conjugais. Psicologia: Ciência e Profissão, 36(1): 171-182. doi:10.1590/1982-3703003832015

How to Cite: Cecílio, M. S., \& Scorsolini-Comin, F. (2016). PAdoptive and biological parenthoods and their impact on marital dynamics. Psicologia: Ciência e Profissão, 36(1): 171-182. doi:10.1590/1982-3703003832015

Cómo citar: Cecílio, M. S., \& Scorsolini-Comin, F. (2016). Paternidad adoptiva y biológica y sus repercusiones en las dinámicas conyugales. Psicologia: Ciência e Profissão, 36(1): 171-182. doi:10.1590/1982-3703003832015 